\title{
Diastolic aortic pressure rise during percutaneous transluminal coronary angioplasty: an index of left ventricular systolic dysfunction
}

Ioannis A Paraskevaidis, Zenon S Kyriakides, Antonis K Kassimatis, Thomas P Apostolou, George K Kalopisis, Dimitrios Th Kremastinos

\begin{abstract}
Objectives-To investigate the relation between diastolic aortic pressure response and left ventricular systolic dysfunction during percutaneous transluminal coronary angioplasty.

Background-The abnormal diastolic blood pressure rise during exercise in patients with coronary artery disease probably reflects left ventricular systolic dysfunction rather than the number of stenosed coronary arteries.

Methods-Aortic blood pressures and left ventricular systolic function indices were estimated in 26 patients with single proximal stenosis of the left anterior descending coronary artery both before and during angioplasty.

Results-During coronary angioplasty all patients presented an increase in diastolic aortic pressure $(P \ll 0.001)$, 8-12 s before intracoronary electrocardiographic changes. During acute ischaemia there was a decrease in left ventricular ejection fraction $(P \ll 0.001)$ and stroke volume $(P \ll 0.001)$ and an increase in end systolic volume (P $\ll 0.001)$ and left ventricular end diastolic pressure (P $\ll 0 \cdot 001)$. No statistically significant changes were observed in systolic blood pressure or heart rate. The aortic diastolic pressure increase was correlated with the decrease in ejection fraction $(r=-0.95, P \ll 0.001)$ and with the increases in end systolic volume $(r=0.86, P \ll 0.001)$ and left ventricular end diastolic pressure $(r=0.85$, P $\ll 0.001)$.

Conclusions-The rise in diastolic aortic pressure during percutaneous transluminal coronary angioplasty occurs earlier than intracoronary electrocardiographic changes and is related to ischaemic left ventricular systolic dysfunction.
\end{abstract}

(Br Heart $\mathcal{F} 1995 ; 74: 242-246)$

Keywords: diastolic aortic pressure; left ventricular systolic dysfunction; coronary angioplasty

Although systolic blood pressure behaviour has been extensively studied in patients with coronary artery disease ${ }^{12}$ and well correlated with myocardial ischaemia ${ }^{34}$ there are few data on diastolic blood pressure response during ischaemia. We and others have recently shown that the rise of diastolic blood pressure during stress testing in patients with coronary artery disease is an index of latent left ventricular systolic dysfunction ${ }^{56}$ and is not correlated with the number of stenotic arteries, as others have previously suggested..$^{78}$ In all studies diastolic blood pressure was measured during stress induced ischaemia, while the indices of left ventricular systolic function were measured at rest. Percutaneous transluminal coronary angioplasty offers a unique opportunity to study the sequential changes in left ventricular function during transient occlusion of the vessel and thus during acute myocardial ischaemia. It has been well documented that during coronary angioplasty there is an impairment of the haemodynamic indices of left ventricular systolic function. ${ }^{9-12}$ Although an increase in diastolic blood pressure has been observed during coronary angioplasty ${ }^{13}$ no relation between diastolic blood pressure and left ventricular haemodynamic variables was found.

The purpose of this study was to investigate the relation between diastolic aortic blood pressure response and left ventricular systolic dysfunction during percutaneous transluminal coronary angioplasty.

\section{Methods}

\section{STUDY PATIENTS}

Twenty six patients (22 male and four female), aged 56 (SD 10) years with left anterior descending coronary artery disease were included in this study. All patients had a history of stable angina (Canadian Heart Association, classes III-IV) and were in New York Heart Association functional class I. All patients were receiving oral antianginal treatment (stopped 24 hours before the procedure), sublingual glyceryl trinitrate (when necessary), and aspirin, while 23 of them were also taking $\beta$ blocker medication which was stopped three days before the procedure. None of the patients had had angioplasty of a totally occluded artery or had a history of myocardial infarction or hypertension. Coronary angiography, performed two to five weeks before angioplasty, showed significant proximal left anterior descending artery stenosis (defined as $>85 \%$ of lumen diameter).

CARDIAC CATHETERISATION AND ANGIOPLASTY PROTOCOL

All patients underwent left heart catheterisation by the Seldinger technique. A pigtail 
catheter was introduced into the left ventricle via the left femoral artery. Evaluations immediately before angioplasty included initial haemodynamic recordings (with the use of fluid filled catheters) consisting of left ventricular and aortic pressures (ascending aorta) followed by contrast left ventricular angiography ( $30^{\circ}$ right anterior oblique). Special care was taken to ensure that the fluid in the cannula, tubing, and transducer dome was free of air bubbles. Without premedication, percutaneous transluminal coronary angioplasty (90 s; $8 \mathrm{~atm}$ ) was performed after left ventricular and aortic pressures had returned to preventriculography values (11-15 $\mathrm{min}$ to be certain). The guiding catheter for the coronary angioplasty procedure was introduced through the right femoral artery. Patients were monitored during the procedure with a threelead electrocardiogram (ECG leads $D_{1}, D_{2}$, and intracoronary). Continuous ECG, left ventricular pressure, and aortic pressure recordings were made simultaneously during angioplasty. Balloon dilatation catheters and guide wires of variable sizes were used as clinically indicated. During angioplasty, and more specifically $40-50 \mathrm{~s}$ after balloon inflation, haemodynamic variables and the second left ventriculography ${ }^{111415}$ from the same view were obtained using the same procedure. In patients who developed angina $(n=4)$ earlier than $50 \mathrm{~s}$ during angioplasty, haemodynamic variables and left ventriculography were obtained immediately. All patients gave their written informed consent to the procedure. The study was approved by the hospital's ethics committee.

\section{DERIVED CALCULATION}

Left ventriculography was performed for the determination of end systolic and end diastolic volume and ejection fraction both before and during angioplasty. Stroke volume was measured by subtracting end diastolic from end systolic volume. Left ventricular end diastolic and systolic pressures, and aortic systolic and diastolic pressures were also estimated both before and during angioplasty. All haemodynamic variables were determined before left ventriculography was performed.

\section{STATISTICS}

All values are expressed as mean (SD). The $t$ test for paired data was used for values before and during angioplasty. Linear regression analysis was used to correlate the diastolic blood pressure difference (beforeduring acute ischaemia) with the haemodynamic variables. A $P$ value $<0.05$ was considered statistically significant.

\section{Results}

The main haemodynamic findings before and after coronary angioplasty are shown in table 1. All patients had a statistically significant increase $(13.9(5.9) \mathrm{mm} \mathrm{Hg})$ in diastolic aortic pressure (figure). Fifteen out of 26 patients developed angina during coronary angioplasty and an ST segment deviation (seven with elevation; eight with depression) 8-12 s after the increase in diastolic aortic pressure. During angioplasty there were decreases in ejection fraction $(14 \cdot 2(6 \cdot 3) \%)$ and in stroke volume $\left(13(6 \cdot 5) \mathrm{ml} / \mathrm{m}^{2}\right)$ whereas there were increases in left ventricular end diastolic pressure $(13 \cdot 1(7 \cdot 0) \mathrm{mm} \mathrm{Hg})$, end

Table 1 Haemodynamic findings before and during coronary angioplasty $(n=26)$. Values are means $(S D)$

\begin{tabular}{llll}
\hline & Before & During & P value \\
\hline SAP (mm Hg) & $134(14)$ & $134 \cdot 8(12)$ & NS \\
DAP (mm Hg) & $73 \cdot 4(10 \cdot 6)$ & $89 \cdot 6(16 \cdot 1)$ & $<0 \cdot 00001$ \\
EF (\%) & $59 \cdot 6(11 \cdot 3)$ & $45 \cdot 4(13 \cdot 5)$ & $<0 \cdot 00001$ \\
LVEDP (mm Hg) & $10 \cdot 3(1 \cdot 7)$ & $23 \cdot 4(7 \cdot 9)$ & $<0 \cdot 00001$ \\
ESV (ml/m2) & $28 \cdot 9(2 \cdot 3)$ & $54 \cdot 6(8 \cdot 4)$ & $<0 \cdot 00001$ \\
EDV (ml/m2) & $85 \cdot 6(4 \cdot 7)$ & $95 \cdot 5(5 \cdot 7)$ & $<0 \cdot 00001$ \\
SV (m1/m2) & $55 \cdot 9(5 \cdot 1)$ & $42 \cdot 8(8 \cdot 0)$ & $<0 \cdot 00001$ \\
mBP (mm Hg) & $95(12 \cdot 5)$ & $104 \cdot 6(12 \cdot 9)$ & $<0 \cdot 00001$ \\
HR (beats/min) & $77 \cdot 7(4 \cdot 2)$ & $78 \cdot 1(3)$ & NS \\
\hline
\end{tabular}

SAP, systolic aortic blood pressure; DAP, diastolic aortic blood pressure; EF, ejection fraction; LVEDP, left ventricular end diastolic pressure; ESV, end systolic volume; EDV, end diastolic volume; SV, stroke volume; mBP, mean blood pres-

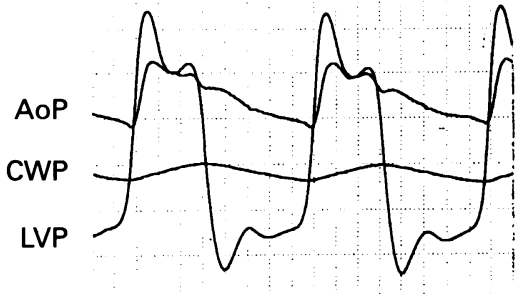

Before angioplasty $1,1,1,1,1,1,1,111,1111$
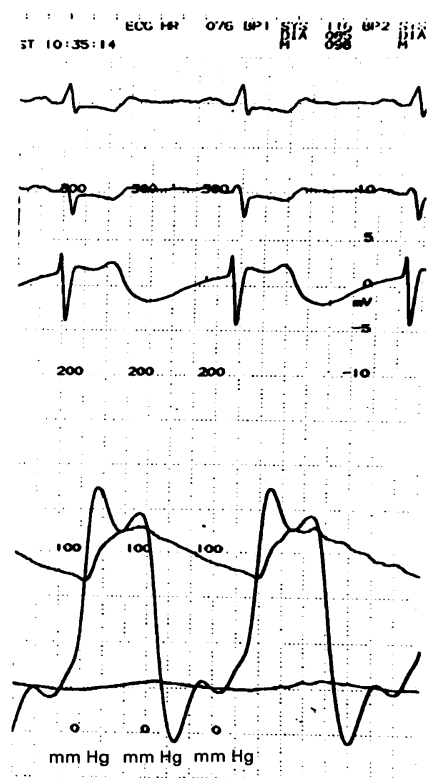

During angioplasty

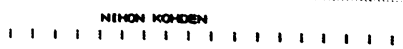

Increase in aortic diastolic pressure during percutaneous transluminal coronary angioplasty recorded simultaneously with an increase in left ventricular end diastolic pressure. AoP, aortic pressure; $C W P$, coronary wedge pressure; $D 1, D 2, I C E$, electrocardiographic leads D1, D2 and intracoronary; LVP, left ventricular pressure
Table 2 Correlation coefficients of difference in aortic diastolic pressure before and during coronary angioplasty compared with differences in the haemodynamic variety $(n=26)$

\begin{tabular}{lllll}
\hline & & $d E F$ & $d E S V$ & $d L V E D P$ \\
\hline \multirow{2}{*}{ dDAP } & $r:$ & -0.95 & 0.86 & 0.85 \\
& P: & $<0.0001$ & $<0.0001$ & $<0.0001$ \\
\hline
\end{tabular}

d, difference between values before and during angioplasty; EF, ejection fraction; ESV, end systolic volume; LVEDP, left ventricular end diastolic volume. 
Table 3 Haemodynamic findings from the individual patients

\begin{tabular}{|c|c|c|c|c|c|c|c|c|c|c|c|c|}
\hline Patient & $\begin{array}{l}S A P_{1} \\
(m m H g)\end{array}$ & $\begin{array}{l}D A P_{1} \\
(m m H g)\end{array}$ & $\begin{array}{l}\mathrm{SAP}_{2} \\
(\mathrm{~mm} \mathrm{Hg})\end{array}$ & $\begin{array}{l}D A P_{2} \\
(m m \mathrm{Hg})\end{array}$ & $\begin{array}{l}d S A P \\
(m m H g)\end{array}$ & $\begin{array}{l}d D A P \\
(m m \mathrm{Hg})\end{array}$ & $\begin{array}{l}m B P_{l} \\
(m m H g)\end{array}$ & $\begin{array}{l}m B P_{2} \\
(m m H g)\end{array}$ & $\begin{array}{l}E F_{I} \\
(\%)\end{array}$ & $\begin{array}{l}E F_{2} \\
(\%)\end{array}$ & $\begin{array}{l}d E F \\
(\%)\end{array}$ & $\begin{array}{l}d m B P \\
(m m H g)\end{array}$ \\
\hline $\begin{array}{r}1 \\
2 \\
3 \\
4 \\
5 \\
6 \\
7 \\
8 \\
9 \\
10 \\
11 \\
12 \\
13 \\
14 \\
15 \\
16 \\
17 \\
18 \\
19 \\
20 \\
21 \\
22 \\
23 \\
24 \\
25 \\
26\end{array}$ & $\begin{array}{r}137 \\
140 \\
120 \\
150 \\
130 \\
113 \\
118 \\
135 \\
118 \\
135 \\
150 \\
125 \\
135 \\
153 \\
95 \\
134 \\
153 \\
135 \\
140 \\
145 \\
155 \\
125 \\
127 \\
142 \\
135 \\
137\end{array}$ & $\begin{array}{l}72 \\
75 \\
72 \\
90 \\
55 \\
63 \\
75 \\
75 \\
75 \\
67 \\
83 \\
68 \\
73 \\
70 \\
55 \\
93 \\
75 \\
61 \\
86 \\
88 \\
85 \\
73 \\
85 \\
75 \\
\mathbf{5 5} \\
65\end{array}$ & $\begin{array}{r}145 \\
140 \\
125 \\
153 \\
138 \\
119 \\
120 \\
137 \\
123 \\
131 \\
150 \\
126 \\
138 \\
155 \\
98 \\
132 \\
148 \\
131 \\
135 \\
142 \\
140 \\
132 \\
130 \\
142 \\
136 \\
139\end{array}$ & $\begin{array}{r}84 \\
76 \\
85 \\
132 \\
59 \\
75 \\
90 \\
85 \\
93 \\
75 \\
100 \\
88 \\
108 \\
97 \\
73 \\
100 \\
98 \\
75 \\
97 \\
106 \\
112 \\
90 \\
103 \\
90 \\
65 \\
73\end{array}$ & $\begin{array}{r}8 \\
0 \\
5 \\
3 \\
8 \\
6 \\
2 \\
2 \\
5 \\
-4 \\
0 \\
1 \\
3 \\
2 \\
3 \\
-2 \\
-5 \\
-4 \\
-5 \\
-3 \\
-15 \\
7 \\
3 \\
0 \\
1 \\
2\end{array}$ & $\begin{array}{r}12 \\
1 \\
13 \\
12 \\
4 \\
12 \\
15 \\
10 \\
18 \\
8 \\
17 \\
20 \\
25 \\
27 \\
18 \\
7 \\
18 \\
14 \\
11 \\
18 \\
20 \\
17 \\
13 \\
15 \\
10 \\
8\end{array}$ & $\begin{array}{r}93.6 \\
96.6 \\
88.0 \\
130.0 \\
80.0 \\
79.6 \\
89.3 \\
95.0 \\
89.3 \\
89.3 \\
105.3 \\
87.0 \\
100.3 \\
97.6 \\
68.3 \\
106.6 \\
104.3 \\
85.6 \\
104.0 \\
107.0 \\
113.0 \\
90.3 \\
102.3 \\
97.3 \\
81.6 \\
89.0\end{array}$ & $\begin{array}{r}104.3 \\
97.3 \\
98.3 \\
139.0 \\
85.3 \\
89.6 \\
100.0 \\
102.3 \\
103.0 \\
93.6 \\
116.6 \\
100.6 \\
118.0 \\
116.3 \\
81.3 \\
110.6 \\
114.6 \\
93.6 \\
109.6 \\
118.0 \\
121.3 \\
104.0 \\
112.0 \\
107.3 \\
88.6 \\
95.0\end{array}$ & $\begin{array}{l}65 \\
80 \\
57 \\
45 \\
52 \\
47 \\
65 \\
70 \\
50 \\
50 \\
50 \\
50 \\
55 \\
52 \\
60 \\
60 \\
75 \\
80 \\
58 \\
54 \\
83 \\
60 \\
40 \\
60 \\
62 \\
70\end{array}$ & $\begin{array}{l}55 \\
75 \\
43 \\
35 \\
48 \\
37 \\
48 \\
62 \\
30 \\
45 \\
31 \\
28 \\
31 \\
27 \\
40 \\
52 \\
55 \\
65 \\
48 \\
34 \\
63 \\
43 \\
25 \\
43 \\
55 \\
63\end{array}$ & $\begin{array}{r}10 \\
5 \\
14 \\
10 \\
4 \\
10 \\
17 \\
8 \\
20 \\
5 \\
19 \\
22 \\
24 \\
25 \\
20 \\
8 \\
20 \\
15 \\
10 \\
20 \\
20 \\
17 \\
15 \\
17 \\
7 \\
7\end{array}$ & $\begin{array}{r}10 \cdot 7 \\
1.3 \\
10.3 \\
9.0 \\
5 \cdot 3 \\
10.0 \\
11 \cdot 7 \\
7 \cdot 3 \\
3.7 \\
4.0 \\
11 \cdot 3 \\
12.4 \\
17.3 \\
18.7 \\
13.0 \\
4.0 \\
10.3 \\
8.0 \\
5.6 \\
11.0 \\
7.7 \\
13.7 \\
9.7 \\
10.0 \\
7.0 \\
6.0\end{array}$ \\
\hline $\begin{array}{l}\text { Mean } \\
\text { (SD) }\end{array}$ & $\begin{array}{l}134 \cdot 0 \\
(14)\end{array}$ & $\begin{array}{l}73 \cdot 4 \\
(10 \cdot 6)\end{array}$ & $\begin{array}{l}134 \cdot 8 \\
(12)\end{array}$ & $\begin{array}{l}89 \cdot 6 \\
(16 \cdot 1)\end{array}$ & $\begin{array}{l}0.9 \\
(4 \cdot 9)\end{array}$ & $\begin{array}{l}13.9 \\
(5.9)\end{array}$ & $\begin{array}{l}95 \\
(12 \cdot 5)\end{array}$ & $\begin{array}{l}104 \cdot 6 \\
(12 \cdot 9)\end{array}$ & $\begin{array}{l}59 \cdot 6 \\
(11 \cdot 3)\end{array}$ & $\begin{array}{l}45 \cdot 4 \\
(13 \cdot 5)\end{array}$ & $\begin{array}{l}14 \cdot 2 \\
(6 \cdot 4)\end{array}$ & $\begin{array}{l}9 \cdot 2 \\
(4 \cdot 1)\end{array}$ \\
\hline
\end{tabular}

Subscript 1, before angioplasty; subscript 2, during angioplasty; SAP, systolic arterial pressure; DAP, diastolic arterial pressure; d, differences between values before and during angioplasty; $\mathrm{mBP}$, mean blood pressure; EF, ejection fraction; LVEDP, left ventricular end diastolic pressure; ESV, end systolic volume; EDV, end diastolic volume; SV, stroke volume, $\mathrm{HR}$, heart rate.

diastolic volume $\left(9.8(3.2) \mathrm{ml} / \mathrm{m}^{2}\right)$ and end systolic volume $\left(25.6(6.4) \mathrm{ml} / \mathrm{m}^{2}\right)$. Heart rate and systolic blood pressure did not change during angioplasty, whereas mean blood pressure increased $(9 \cdot 2(4 \cdot 1) \mathrm{mm} \mathrm{Hg})$.

The correlation coefficients of the difference in aortic diastolic pressure before and during angioplasty compared with differences in the haemodynamic variables are shown in table 2 . The difference in aortic diastolic pressure before and during angioplasty was not correlated significantly with baseline left ventricular function. The individual results for the whole study group are given in table 3 .

\section{Discussion}

This study shows that during percutaneous transluminal coronary angioplasty there is an increase in mean aortic pressure because of an increase in diastolic aortic pressure. This increase in diastolic blood pressure precedes the intracoronary electrocardiographic changes and is well correlated with the impairment of left ventricular systolic function when myocardial ischaemia occurs.

DIASTOLIC AORTIC PRESSURE AND LEFT VENTRICULAR HAEMODYNAMIC CHANGES

Since the systolic aortic pressure before and during coronary angioplasty was similar in all patients, the increase in mean aortic pressure was related to the increase in diastolic aortic pressure. This increase was well correlated with the left systolic ventricular function, expressed by a decrease in ejection fraction and stroke volume, and an increase in left ventricular end systolic volume and end diastolic pressure. The impairment of left ventricular systolic function during coronary angioplasty has been well established in previ- ous studies where left ventricular systolic dysfunction during angioplasty was reported in experimental animals ${ }^{16}{ }^{17}$ and humans. ${ }^{811}$ More specifically, it has been suggested that during angioplasty there is a reduction of left ventricular systolic function which is characterised by a rightward displacement of the end systolic pressure-volume relation. ${ }^{8}$

MECHANISM OF BLOOD PRESSURE CHANGES Although diastolic blood pressure is the primary determinant of arterial baroreflex neuroeffector responses in humans, ${ }^{18}$ the exact mechanism by which diastolic blood pressure is raised is not totally clear. It has been suggested that there is a muscle afferent feedback mechanism, whereby signals are sent from receptors in contracting muscle to the brain, stimulating sympathetic centres, ${ }^{19}$ or most likely excited through a metabolic mechanism. ${ }^{20}$ Moreover, it has been shown that there is a greater increase in mean arterial pressure when the muscle is rendered ischaemic than when ischaemia is absent. ${ }^{21}$ Inadequate cardiac output relative to local tissue demands, generating ischaemia, would therefore affect blood pressure responses.

When the heart is coupled to the circulation the resulting pressure and flow are determined by the mutual mechanical interaction of the ventricle and the circulation, and not by either one or other acting independently. ${ }^{22}$ In this respect, the physiological terms "cardiac output" and "arterial pressure", which refer to the flow and pressure determined by the joint interaction of the heart and circulation, could be misleading. In the diseased ventricle the mutual interaction between the ventricular pump and the arterial load becomes more pronounced. ${ }^{23}$ Maintenance of a normal or nearly normal level of arterial pressure is 


\begin{tabular}{|c|c|c|c|c|c|c|c|c|c|c|c|c|c|}
\hline $\begin{array}{l}L V E D P_{1} \\
(m m \mathrm{Hg})\end{array}$ & $\begin{array}{l}L V E D P_{2} \\
(m m ~ H g)\end{array}$ & $\begin{array}{l}\text { DLVEDP } \\
\text { (mm Hg) }\end{array}$ & $\begin{array}{l}E S V_{l} \\
(m m ~ H g)\end{array}$ & $\begin{array}{l}E S V_{2} \\
(m m ~ H g)\end{array}$ & $\begin{array}{l}d E S V \\
(\mathrm{~mm} \mathrm{Hg})\end{array}$ & $\begin{array}{l}E D V_{I} \\
(m m \mathrm{Hg})\end{array}$ & $\begin{array}{l}E D V_{2} \\
(m m \mathrm{Hg})\end{array}$ & $\begin{array}{l}d E D V \\
(m m \mathrm{Hg})\end{array}$ & $\begin{array}{l}S V_{1} \\
\left(\mathrm{ml} / \mathrm{m}^{2}\right)\end{array}$ & $\begin{array}{l}S V_{2} \\
\left(\mathrm{ml} / \mathrm{m}^{2}\right)\end{array}$ & $\underset{\left(m l / m^{2}\right)}{d S V}$ & $\begin{array}{l}H R_{I} \\
\text { (beats/min) }\end{array}$ & $\begin{array}{l}H R_{2} \\
\text { (beats/min) }\end{array}$ \\
\hline 9 & 16 & 7 & 27 & 47 & 20 & 80 & 89 & 9 & 53 & 42 & 9 & 78 & 79 \\
\hline 11 & 16 & 5 & 26 & 42 & 16 & 81 & 91 & 10 & 55 & 49 & 6 & 81 & 83 \\
\hline 10 & 19 & 9 & 27 & 52 & 25 & 75 & 88 & 13 & 48 & 36 & 12 & 76 & 75 \\
\hline 9 & 14 & 5 & 28 & 46 & 18 & 80 & 85 & 5 & 52 & 39 & 13 & 85 & 81 \\
\hline 10 & 19 & 9 & 28 & 56 & 28 & 80 & 95 & 15 & 52 & 49 & 3 & 82 & 79 \\
\hline 11 & 22 & 11 & 30 & 62 & 32 & 90 & 100 & 10 & 60 & 38 & 22 & 83 & 80 \\
\hline 8 & 14 & 6 & 27 & 50 & 23 & 90 & 98 & 8 & 63 & 48 & 15 & 80 & 80 \\
\hline 10 & 14 & 4 & 27 & 47 & 20 & 90 & 97 & 7 & 53 & 50 & 3 & 69 & 71 \\
\hline 9 & 22 & 13 & 29 & 58 & 29 & 85 & 92 & 7 & 46 & 34 & 12 & 74 & 76 \\
\hline 10 & 35 & 25 & 31 & 62 & 31 & 90 & 102 & 12 & 59 & 40 & 19 & 76 & 77 \\
\hline 8 & 32 & 24 & 34 & 69 & 35 & 85 & 100 & 15 & 51 & 31 & 20 & 81 & 79 \\
\hline 10 & 34 & 24 & 33 & 67 & 34 & 88 & 105 & 17 & 55 & 38 & 17 & 77 & 75 \\
\hline 13 & 28 & 15 & 29 & 58 & 29 & 88 & 95 & 7 & 59 & 37 & 22 & 73 & 75 \\
\hline 9 & 16 & 7 & 27 & 45 & 18 & 92 & 101 & 9 & 65 & 56 & 9 & 79 & 81 \\
\hline 12 & 38 & 26 & 32 & 65 & 33 & 92 & 101 & 9 & 60 & 56 & 4 & 72 & 75 \\
\hline 10 & 21 & 11 & 29 & 51 & 22 & 88 & 95 & 7 & 59 & 44 & 15 & 81 & 79 \\
\hline 11 & 19 & 8 & 26 & 43 & 17 & 83 & 90 & 7 & 57 & 47 & 10 & 85 & 81 \\
\hline 13 & 35 & 22 & 31 & 66 & 35 & 90 & 103 & 13 & 59 & 37 & 22 & 82 & 82 \\
\hline 11 & 21 & 10 & 26 & 47 & 21 & 85 & 100 & 15 & 59 & 53 & 6 & 76 & 79 \\
\hline 14 & 34 & 20 & 30 & 60 & 30 & 83 & 91 & 8 & 53 & 31 & 22 & 74 & 74 \\
\hline 9 & 16 & 7 & 27 & 44 & 17 & 86 & 92 & 6 & 59 & 48 & 11 & 72 & 74 \\
\hline 8 & 19 & 11 & 28 & 47 & 19 & 88 & 100 & 12 & 60 & 53 & 7 & 79 & 79 \\
\hline $\begin{array}{l}10 \cdot 3 \\
(1 \cdot 7)\end{array}$ & $\begin{array}{l}23 \cdot 4 \\
(7 \cdot 9)\end{array}$ & $\begin{array}{l}13 \cdot 1 \\
(7 \cdot 0)\end{array}$ & $\begin{array}{l}28 \cdot 9 \\
(2 \cdot 3)\end{array}$ & $\begin{array}{l}54 \cdot 6 \\
(8 \cdot 4)\end{array}$ & $\begin{array}{l}25 \cdot 6 \\
(6 \cdot 4)\end{array}$ & $\begin{array}{l}85 \cdot 6 \\
(4 \cdot 7)\end{array}$ & $\begin{array}{l}95 \cdot 5 \\
(5 \cdot 7)\end{array}$ & $\begin{array}{l}9 \cdot 9 \\
(3 \cdot 3)\end{array}$ & $\begin{array}{l}55 \cdot 9 \\
(5 \cdot 1)\end{array}$ & $\begin{array}{l}42 \cdot 8 \\
(8 \cdot 0)\end{array}$ & $\begin{array}{l}13 \\
(6 \cdot 5)\end{array}$ & $\begin{array}{l}77 \cdot 7 \\
(4 \cdot 2)\end{array}$ & $\begin{array}{l}78 \cdot 1 \\
(3 \cdot 0)\end{array}$ \\
\hline
\end{tabular}

important, not only for pressure control itself, but also because it allows adequate blood flow through the tissues. ${ }^{24}$ Thus, during percutaneous transluminal coronary angioplasty, where the ventricular pump function is reduced, the circulatory system has to respond accordingly. In this respect, in our study the attempt to maintain the mean blood pressure near normal might be due to systemic resistance increases, since systolic pressure was not significantly changed, stroke volume was decreased, and there was no change in heart rate. Recent studies support this view by showing that during coronary angioplasty, when a major coronary artery is totally blocked, there is a rise in peripheral resistance. ${ }^{25}$ This is due to the flattening of the arterial pressure curve caused by the decreased pulse pressure, equivalent to the reduction of the arterial peak $\mathrm{dP} / \mathrm{dt}^{25}{ }^{26}$ Thus it could be assumed that during percutaneous transluminal coronary angioplasty the decrease in cardiac output led to an increase in peripheral resistance and to a rise in diastolic blood pressure.

RELATION TO INTRACORONARY ECG CHANGES Finally, this study shows that during acute ischaemia the diastolic aortic blood pressure increased before intracoronary ECG changes. The earlier appearance of the rise in diastolic pressure is in accordance with previous studies $^{56}$ and is not paradoxical, since haemodynamic changes are known to precede the electrocardiographic findings.

LIMITATIONS OF THE STUDY

Firstly, systemic resistance was not measured since the changes in oxygen consumption and thus the measurement of cardiac output during a short period of time such as during coro- nary angioplasty are inaccurate. Secondly, stroke volume, velocity of ejection, cardiac output, and left ventricular performance might influence distensibility of the aorta $a^{27}$ and subsequently the response of aortic blood pressure. In this respect, a multivariable analysis of the above variables in a large study population might clarify our findings further.

\section{Conclusions}

In this study it has been shown that during acute ischaemia there is an impairment of left ventricular systolic function, probably leading to an increase in systemic arterial resistance and thus to an increase in the diastolic aortic blood pressure. The increase in diastolic aortic pressure occurs before intracoronary ECG changes and is well correlated with ischaemic left ventricular dysfunction. These findings support the view that the increase in diastolic blood pressure is an index of left ventricular systolic dysfunction when myocardial ischaemia occurs.

We thank Eleni Binou for her secretarial assistance in preparing this manuscript.

1 Ellestand HM. Stress testing, 3rd edition, Ellestand HM. Blood pressure measurements during exercise. Philadelphia: FA Davis, 1986:355-66.

2 Morris SN, Philips JF, Jordan JW, McHenry PL. Incidence and significance of decrease in systolic blood pressure during graded treadmill exercise testing. $\mathrm{Am} \mathcal{F}$

3 Irving JB, Bruce RA, DeRouen TA. Variation in and significance of systolic pressure during maximal (treadmill) testing: relation to severity of coronary artery disease and testing: relation to severity of coronary artery dis

cardiac mortality. Am f Cardiol 1977;39:841-8.
4 Willerson JT, Hillis LD, Buja LA. Ischemic heart disease. New York: Raven Press, 1983:171-9.

5 Paraskevaidis JA, Kremastinos DT, Kassimatis AS, et al. Increased diastolic blood pressure response to exercise in coronary artery disease patients: an index of latent ventricular dysfunction? Br Heart f 1993;69:507-11.

6 Akhras F, Jackson G. Raised exercise diastolic blood pressure as indicator of ischaemic left ventricular dysfunction. Lancet 1991;337:899-900.

7 Akhras F, Upward J, Jackson G. Increased diastolic blood pressure response to exercise testing when coronary 
artery disease is suspected: an indication of severity. Br Heart $₹$ 1985;53:598-602.

8 Sheps SD, Ernst CJ, Briese WF, Myerburg RJ. Exerciseinduced increase in diastolic pressure: indicator of severe coronary artery disease. Am f Cardiol 1979;43:708-12.

9 Kass DA, Midei M, Brinker J, Maughan L. Influence of coronary occlusion during PTCA on end-systolic and end-diastolic pressure-volume relation in humans. Circulation 1990;81:447-60.

10 Carlson EB, Cowley MJ, Wolfgang TC, Vetrovec GW. Acute changes in global and regional rest left ventricular function after successful angioplasty: comparative results in stable and unstable angina. $\mathcal{F} \mathrm{Am}$ Coll Cardiol 1989; in stable and

11 Bertrand ME, LaBlanche JM, Fourrier JL, Traisnel G, Mirsky I. Left ventricular systolic and diastolic function during acute coronary artery balloon occlusion in humans. F Am Coll Cardiol 1988;12:341-7.

12 Serruys PW, Wijns W, van den Brand $M$, et al. Left ventricular performance, regional blood flow, wall motion and lactate metabolism during transluminal angioplasty. Circulation 1984;70:25-36.

13 Verani SM, Lacy LJ, Guidry WG, et al. Quantification of left ventricular performance during transient coronary occlusion at various anatomic sites in humans: a study using tantalum-178 and a multiwire gamma camera. using Coll Cardiol 1992;19:297-306.

14 Wohlgelernter D, Jaffe CC, Cabin HS, Yeatma LA, Cleman M. Silent ischemia during coronary occlusion produced by balloon inflation: relation to regional produced by balloon inflation: relation to regional
myocardial dysfunction. $\mathcal{f} \mathrm{Am}$ Coll Cardiol 1987;10: myocardia.

15 Jaffe CC, Wohlgelernter D, Cabin $\mathrm{H}$, et al. Preservation of left ventricular ejection during percutaneous transluminal coronary angioplasty by distal transcatheter coronary perfusion of oxygenated Fluosol DA $20 \%$. Am Heart $f$ 1988;115:1156-64.

16 Little WC, Roarke RA. Effect of regional ischemia on the left ventricular end-systolic pressure-volume relation in chronically instrumented dogs. $\mathcal{F}$ Am Coll Cardiol 1985; 5:297-302.
17 Kass DA, Marino P, Maughan WL, Sagawa K. Determinants of end-systolic pressure-volume relations during acute regional ischemia in situ. Circulation 1989; 80:1783-94.

18 Sanders JS, Ferguson DW. Diastolic pressure determines autonomic responses to pressure perturbation in humans. Am Physiol Soc 1989:800-7.

19 Smith EE, Guyton AC, Manning RD, White RJ Integrated mechanism of cardiovascular response and control during exercise in the normal human. Prog control during exercise in the
Cardiovasc Dis $1976 ; 18: 421-43$.

$20 \mathrm{McCloskey}$ DI, Mitchell JH. Reflex cardiovascular and respiratory responses originating in exercising muscle. respiratory responses originating in
f Physiol (Lond) 1972;224:173-86.

21 Coote JH, Hilton SM, Perez-Gonzales JR. The reflex nature of the pressor response to muscular exercise. f Physiol (Lond) 1971;215:789-804.

22 Gault JH, Ross J, Braunwald E. Contractile state of the left ventricle in man. Instantaneous tension-velocity length relations in patients with and without disease of the left ventricular myocardium. Circulation 1968;22:451-63.

23 Weber KT, William HC, Shroff S, Pearlman ES, Fishman AP. The contractile behavior of the heart and its functional coupling to the circulation. Prog Cardiovasc Dis 1982;5:375-400.

24 Guyton AC. The relationship of cardiac output and arterial pressure control. Circulation 1981;6:1079-88.

25 Mohr R, Rath S, Meir O, et al. Changes in systemic vascular resistance detected by the arterial resistometer: preliminary report of a new method tested during percutaneous transluminal coronary angioplasty. percutaneous transluminal
Circulation 1986;74:780-5.

26 Chierchia S, Brunelli C, Simonetti I, Lazzari M, Maseri A. Sequence of events in angina at rest: primary reduction in coronary flow. Circulation 1980;61:759-63.

27 Emmanuelsson $\mathrm{H}$, Holumberg S, Selin K, Wallin J. Factors that modify the flow response to intracoronary injection. Circulation 1985;72:287-91.

28 Ferguson JJ, Randall OS. Clinical correlates of arterial compliance (abstr). Circulation 1983;68(suppl III):III132. 